\title{
Quality Analysis of Pomegranate by Non-Destructive Soft X-Ray Method
}

\section{Payel G* and Sunil CK}

Indian Institute of Crop Processing Technology, Thanjavur, India

\begin{abstract}
Pomegranate production in India is 772000 MT in 2011-2012 (NHB Database 2012), which is considered as very nutritive fruit, rich in vitamin B, vitamin A, thiamine, riboflavin, niacin, vitamin $C$ and minerals (potassium, calcium, magnesium, phosphorus, iron). For consumer awareness and export quality grade, grading and sorting of fruits is necessary. Defect of internal break down causes browning or blackening of arils, which gives a typical foul smell if unnoticed. These internal defects cannot be identified from external appearance, which is a serious threat to the pomegranate processing industry as well as export resulting in rejections and quality reduction. X-ray inspection has a distinct advantage over other detection techniques, as it is non-destructive imaging of interior features of sample which detects internal defects. Soft X-ray emission spectroscopy is an experimental technique for determining the electronic structure of materials. A continuous soft X-ray system with a semi-conductor detector was used to detect the internal quality of the fruit. Thus the present study is one of soft X-ray technique to find the internal defects in pomegranate. As to conquer and sustain the international market, there is a need for export of high quality products with no internal defects. The objectives of this study is to determine the internal defects in pomegranate using soft $\mathrm{x}$ ray and to develop the algorithm for classification of defective pomegranate from healthy one.
\end{abstract}

Keyword: Soft X-ray; Pomegranate; Internal quality analysis; Image processing

\section{Introduction}

Pomegranate belongs to the Punicacea family and is one of the oldest known edible fruits. It is sometimes called as Chinese apple, and has been cultivated extensively in Mediterranean countries, Iran, Afghanistan and India and to some extent in the US (California), China, Japan and Russia. The surface colour of the fruit varies from yellow with a crimson cheek, to a solid brownish-red and brightred, among commercial cultivars. There are several types of edible pomegranate and few ornamental types with double flowers, mostly sterile, not grown for edible fruit [1].

Pomegranate is considered as very nutritive fruit rich in vitamin $\mathrm{B}$, vitamin $\mathrm{A}$, thiamine, riboflavin, niacin, vitamin $\mathrm{C}$ and minerals (potassium, calcium, magnesium, phosphorus, iron). In tropical and subtropical area it is largely used as dessert fruit and for fresh juice [2] and health drinks. The edible portion of this fruit is the bright-red pulp (aril) surrounding the individual seed. These arils are consumed directly or processed into juice, syrups, jams or wine.

India is the largest producer of fruits in the world. In which the production of Pomegranate was 772000 MT in 2011-2012 (NHB Database 2012) which was cultivated in 112000 hectares. It is available all through the year. India plays a significant role in export of pomegranate mainly because of the increase in production of quality produce and growth in export value over the years. During 2011-2012, 30158 MT of pomegranate was exported which resulted a value of Rs. 14727 lakhs (APEDA Database). It has been estimated that during the year 2012-2013 pomegranate export will be 36026 MT resulting in a value of Rs 23448 lakhs. Thus the potential of pomegranate export is growing over the years. The major countries which import from India are UAE, Bangladesh, UK, USA, Russia, Nepal, South East Asian countries and few African countries.

For consumer awareness and export quality grade, grading and sorting of fruits is necessary. External quality such as size, shape, colour, tenderness, hardness is evaluated based on visual judgment and hand feel. This subjective grading and sorting causes a risk in processing and export. Internal defects such as bruises, dead tissues, brown discoloration of the white segments, pale aril colour, arils flattened with less colours, blackened arils mass caused by heart rot [3], and internal feeders such as weevils cannot be identified using human senses and naked eye. Defect of internal break down causes browning or blackening of arils, which gives a typical foul smell if unnoticed. These internal defects cannot be identified from external appearance. These cause a serious threat to the pomegranate processing industry as well as export resulting in rejections and quality reduction.

Computer vision opens up a possibility of internal defects detection as manual sorting/inspection is subjective. Many computer vision systems have been developed for the quality inspection of food. Machine vision, using visible light cameras, is a common vision system used for inspection of surface defects of the food, such as bruises, external colour, mechanical damages etc. Colour sorter, infrared thermography, ultrasound, electrical impedance tomography, X-ray tomography, microwave radiometry, and Magnetic Resonance Imaging (MRI) are available to detect the internal defects of biological materials.

$\mathrm{X}$-ray inspection has a distinct advantage over other detection techniques, as it is non-destructive imaging of interior features of sample which detects internal defects. This has become increasingly common in recent years in food industries of processed foods, packaged foods, canned foods, etc., due to increase in emphasis on food safety. There are two types of rays in X-ray which are known as, hard X-ray (energies above 5-10 keV \& below 0.2-0.1 nm wavelength) and soft $\mathrm{X}$-ray with low energy (Figure 1).

Butz [4] stated every possible non-destructive technique for the quality evaluation of the fruits and vegetables. According to the quality components of fruits and vegetables are classified into external

*Corresponding author: Payel Ghosh, Indian Institute of Crop Processing Technology, Thanjavur, India, Tel: 918903436247; E-mail: payelghosh89@gmail.com

Received May 02, 2014; Accepted June 25, 2014; Published July 03, 2014

Citation: Payel G, Sunil CK (2014) Quality Analysis of Pomegranate by NonDestructive Soft X-Ray Method. J Food Process Technol 5: 341. doi:10.4172/2157. 7110.1000341

Copyright: @ 2014 Payel G, et al. This is an open-access article distributed under the terms of the Creative Commons Attribution License, which permits unrestricted use, distribution, and reproduction in any medium, provided the original author and source are credited. 
Citation: Payel G, Sunil CK (2014) Quality Analysis of Pomegranate by Non-Destructive Soft X-Ray Method. J Food Process Technol 5: 341. doi:10.4172/2157-7110.1000341

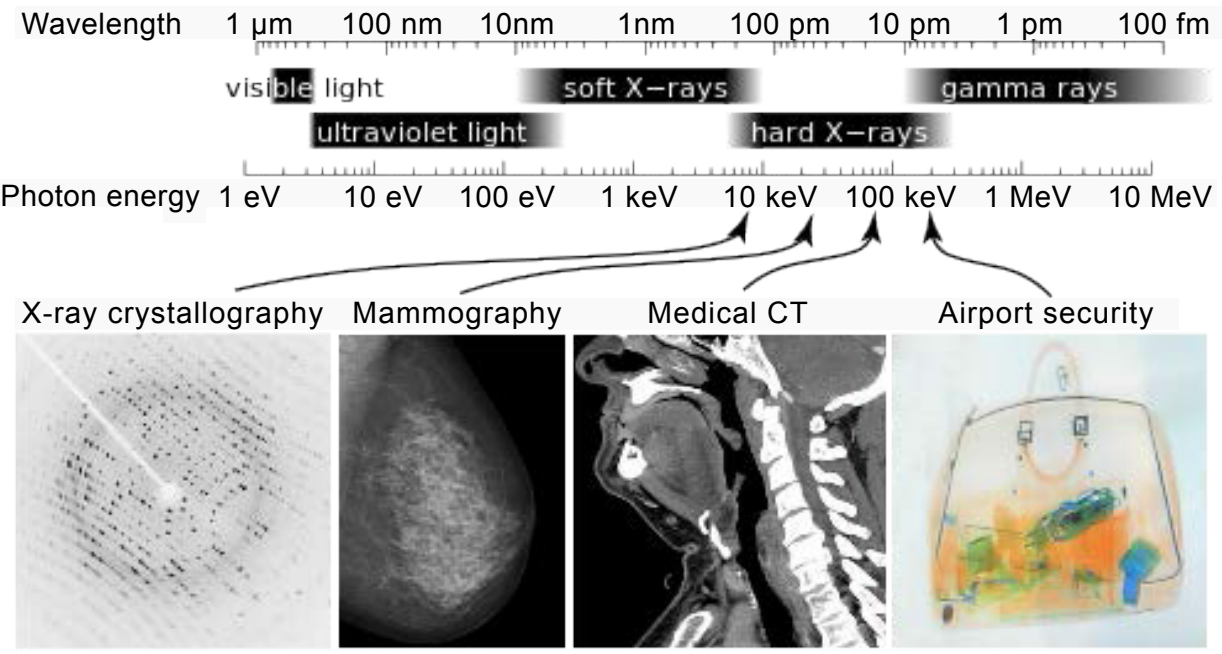

Figure 1: Electromagnetic Spectrum Radiation.

\begin{tabular}{|c|c|c|c|}
\hline Type of Fruit & Voltage $(\mathbf{k V})$ & Current $(\boldsymbol{\mu A})$ \\
\hline Guava & 75 & 125 \\
\hline Pitaya & 75 & 125 \\
\hline Pear & 75 & 125 \\
\hline Apple & 75 & 125 \\
\hline Peach & 65 & 125 \\
\hline Mango & 75 & 0.12 \\
\hline Sunkist & 70 & 0.12 \\
\hline
\end{tabular}

Table 1: The optimum parameters for some familiar imported/exported fruits.

characteristics (size, colour, shape, etc.) and internal (sugar content, acid content, firmness, maturity, internal break downs etc.). Many studies on application of X-ray inspection and quality evaluation have been reported in the field of agriculture. The internal quality and defects of pecan has been checked by Kotwaliwale [5] using digital $\mathrm{X}$-ray image at different voltage and current. In case of apple water core rot determination has been developed by Schatzki [6]. Shahin [7] demonstrated that the extracted image of X-ray can be used to sort defective apples by identifying the bruises in apples. The line scanned $\mathrm{x}$ ray image of the sweet onions, showed that an overall classification accuracy of $90 \%$ can be achieved. X-ray imaging also shown promising results for detecting internal defects in grains. Wheat infested by weevils can be identified using the X-ray imaging [8]. X-ray image was used to measure the mass of wheat by calculating the total grey value of the image by Karunakaran [9]. With the help of soft X-ray insect infestation in guava by Jiang [10], detection of weevil in mango by Thomas and Reyes [11,12], insect infestation in peaches by Jiang et al. translucency in pineapple by Haff [13] has been detected. Blasco et al. [14] invented an automatic sorting machine for pomegranate with the help of image analysis.

Joe-Air Jianga had been established the optimum parameters (Table 1) for some familiar imported/exported fruits via many experiments and equipped in the system database. Therefore the optimum parameters will be set automatically by this program after choosing the type of the inspected fruit by operator.

The Image captured by any machine vision system is to be processed. Morita et al. [15] detected the foreign material from the foods by the help of soft X-ray. Image processing system has been used increasingly in food industry for inspection and evaluation purposes as they can provide rapid, economic, hygienic, consistent and objective assessment. Image processing technique is one of the upcoming commercial up take in food sector. Research is being made in different types of machine vision systems, which has resulted in development of new algorithms and hardware techniques for high speed extraction of features related to quality factors. Thus the present study is one of soft X-ray technique to find the internal defects in pomegranate. As to conquer and sustain the international market, there is a need for export of high quality products with no internal defects. The objectives of this study to determine the internal defects in pomegranate using soft X-ray and to develop the algorithm for classification of defective pomegranate from healthy one.

\section{Materials and Methods}

\section{Samples}

Pomegranate samples of Ruby variety were taken for inspection from the local market. Good fruits as well as fruits with defects were selected from a lot. Selection was done on the basis of random sampling method where manually selection is done by external appearance. 30 fruits were taken for internal detection study using soft X-ray.

\section{Equipment}

$\mathrm{X}$-ray images of pomegranate were acquired using soft X-ray machine in IICPT. The machine consists of 3 sub parts which are $\mathrm{X}$-ray generator controlling unit, transformer and X-ray tube head. By using the generator control values of current $(\mathrm{mA})$, voltage $(\mathrm{kV})$ and time $(\mathrm{sec})$ of exposure can be controlled. The value of $\mathrm{mA}$ and $\mathrm{kV}$ will be set accordingly for the object to be detected. The best combination will be used for capturing best quality image. Transformer generates high 
Citation: Payel G, Sunil CK (2014) Quality Analysis of Pomegranate by Non-Destructive Soft X-Ray Method. J Food Process Technol 5: 341. doi:10.4172/2157-7110.1000341

Page 3 of 6

voltage required for X-ray generation up-to $160 \mathrm{kV}$ and $\mathrm{X}$-rays are generated in X-ray tube head.

Technical Details of the Soft X-ray Machine

\section{$\mathrm{X}$-ray generator}

- $\quad$ Anode voltage $0 \mathrm{kVp}-160 \mathrm{kVp}$ Variable in steps of $1 \mathrm{kV}$

- $\quad$ Tube Head Hermetically sealed oil bath

- $\quad$ Tube Current $0 \mathrm{~mA}-5 \mathrm{~mA}$ variable in steps of $0.1 \mathrm{~mA}$

- Penetration Suitable for all fruits \& vegetables

\section{Image generating system}

- Detector type Area Scan

- $\quad$ Detector Area

$185 \mathrm{~mm}$ x $140 \mathrm{~mm}$

- Image Resolution 2560 x 1920 pixels

- Image Capture Manual Trigger synchronized with the X-Ray Generator

- Image Capture Settings Using software interface installed in computer

\section{Specification}

- $\quad$ Power supply

Stabilized 230V AC single phase $50 \mathrm{~Hz}$

- $\quad$ Power consumption $2.5 \mathrm{kV}$ A maximum

- Humidity 10 to $90 \% \mathrm{RH}$

- Ambient Temperature $150^{\circ} \mathrm{C}$ to $550^{\circ} \mathrm{C}$

\section{Image capture}

The Image quality depends on the values of gain, $\mathrm{kV}$ and $\mathrm{mA}$, as well as exposure time. The best values of these are achieved by trial and error method according to the review of literature mentioned in Table 1 with exposure time of $0.12 \mathrm{~s}$, within the gain value ranged between
40 to 75 , current ranged between 90 to $100 \mathrm{~mA}$, and with a constant voltage of $100 \mathrm{kV}$. Among the above combination best result obtained with 40 gain value, $90 \mathrm{~mA}$ and $100 \mathrm{kV}$ which result in better quality image for further processing.

\section{Image processing}

The images thus acquired by the machine are processed using image processing software (MATLAB 2010b). Algorithm was developed and colour map was used for the detection of the defective fruit.

The Image processing and the defect identification is processed by using the following steps in MATLAB algorithm (Figure 2).

Original images converted to gray scale by eliminating the hue and saturation information while retaining the luminance. Converting it into Black and white image, no of black pixel value was counted which represents the non-defected parts. Increasing the contrast of the image by mapping the values of the input intensity image to new values to make the correct adjustment of the image. The function gray thresh automatically computes an appropriate threshold to use to convert the gray scale image to binary. In thresholding the gray thresh function uses Otsu's method, which chooses the threshold to minimize the intra-class variance of the black and white pixels with an intensity value lies in the range $(0,1)$. Subtraction of the image from the original image to create a more uniform background [16-21]. To provide better performance filling operation was made which traces the exterior boundaries of objects, as well as boundaries of holes inside the objects, in the binary image. Blob Analysis block is used to calculate the statistics for labelled regions in a binary image. The block returns quantities such as the centroid, label matrix, and blob count. After finishing the program we will get the total area of the fruit as well as the non-defected area of the fruit in Black pixel count. So subtracting the black pixel count from total area we will get the defected area, and from that percentage of defected area can be calculated.

In binary image detecting the defect visually is quite difficult. So to make it visible, pictures are also converted into RGB format.

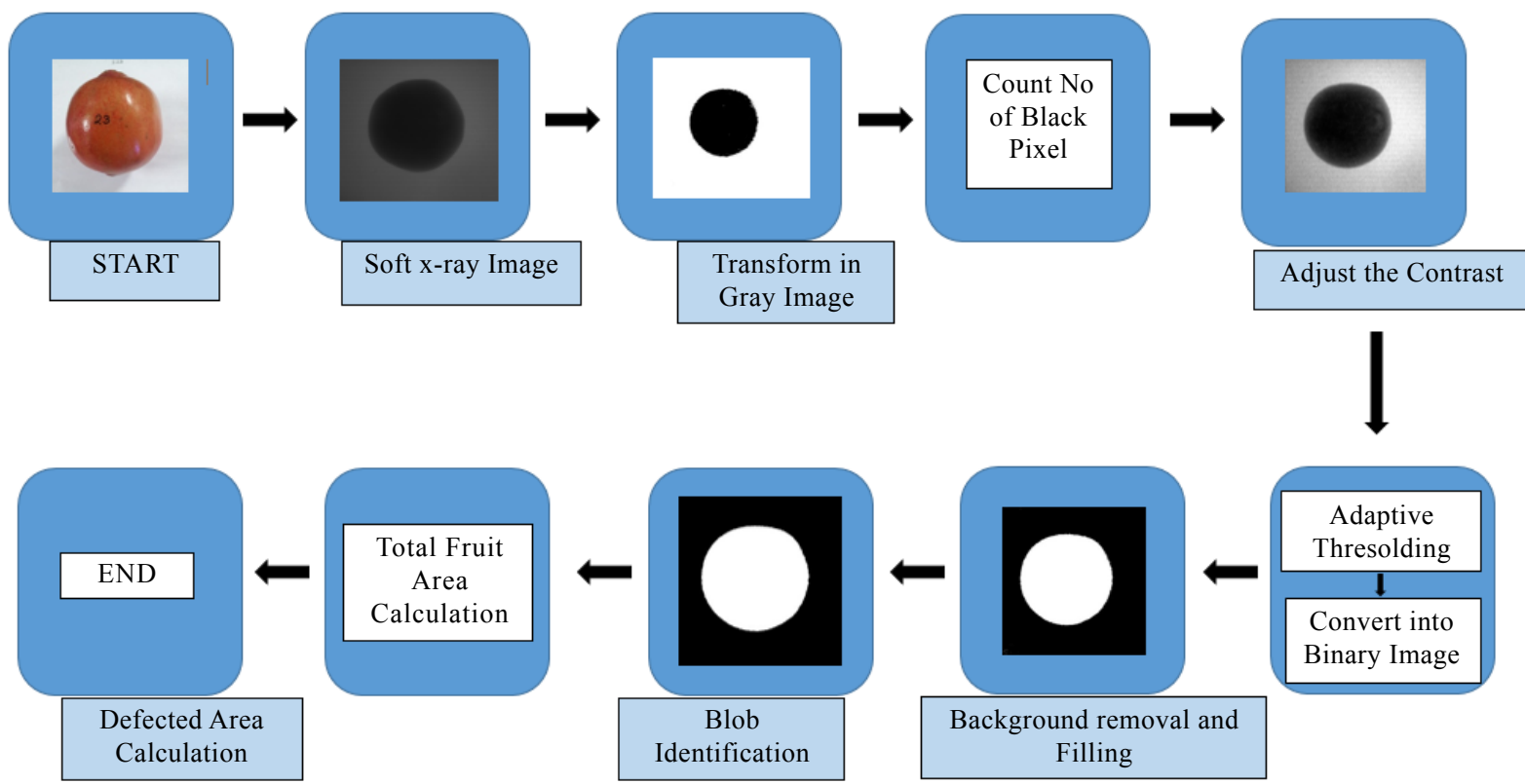

Figure 2: Image Processing in MATLAB for the defective area calculation. 
Citation: Payel G, Sunil CK (2014) Quality Analysis of Pomegranate by Non-Destructive Soft X-Ray Method. J Food Process Technol 5: 341. doi:10.4172/2157-7110.1000341

Page 4 of 6

- Convert into RGB - It converts the picture into a label matrix, into an RGB colour image for the purpose of visualizing the labelled regions. The label2rgb function determines the colour to assign to each object based on the number of objects in the label matrix and range of colours in the colour map.

- Colour-map - Colour-map shows the density variation in the fruits from which differentiation of good and defective fruit is also possible.

\section{Results and Discussions}

Soft X-ray machine was used for capturing the images of pomegranate. Captured images are difficult to differentiate the defective and the good one. This soft X-ray images needs to be further processed as described above.

\section{Method A- RGB images}

Black arils are found in the pomegranate either for over ripening or for mould growth. These types of damages and the defects are not visible from the outside. This non desturctive method is the best way for the explanation and the detection of the internal damages.

Figure 3 described the picture of the original good fruit sample, images of the cut fruit, $x$ ray image and the final processed image. There is no defect inside the sound fruit which gives a uniform colour in the RGB image, whereas Figure 4 is used forth defective fruit. The final RGB image also shows that there is a non-uniformity in the colour and the doted area signifies the defect which matches the defect in the cut fruit.

\section{Method B - Colour-map images}

A colour-map is an m-by- 3 matrix of real numbers between 0.0 and 1.0. The k-th row of the colour-map defines the k-th colour by specifying the intensity of red, green and blue. Colormap is also used to detect the density difference in the fruit.Figure 5 is mentioned below for good fruit as well as for defective fruit. The Good fruit shows the dense and a particular colour where as the defect increases inside the fruit, the intensity of that particular colour decreases. In case of the defective fruit, density difference is due to the less water content in the sample.

Defected area is determined by the proposed algorithm as shown in Figure 6

Defected area is calculated in pixel value as well as in $\mathrm{cm}^{2}$. The range is varied from $(0.21-6.25) \mathrm{cm}^{2}$ with $(0.37-14.46) \%$ of defect. Paired $\mathrm{t}$ test is performed with $95 \%$ significance level. Processed image and the manually calculated area gave the mean of $2.81 \mathrm{~cm}^{2}$ and 2.77 $\mathrm{cm}^{2}$ respectively. Paired standard Deviation is 0.386 with a standard error mean of 0.070 . With 29 degrees of freedom the $t$ value is 0.469 with a $95 \%$ level of significance which implies that processed image gives more accurate result than manually calculated area.

\section{Conclusion}

A real time X-ray system with a work station for analysis captured and sends the images to a computer. The internal defects were differentiated based on X-ray absorption of images. The original X-ray images were not cleared; it was not easy to detect the internal quality of the fruit. Computer algorithms were developed to differentiate between sound and internally defected pomegranate fruits. These algorithms will detect the defects based either on absorption of X-ray and based on processed binary and RGB images. The algorithms were tested by providing samples of sound fruits and samples of fruits with natural and artificially induced defects. The integrity and effectiveness of the developed algorithm were tested based on several samples of sound and defected fruits. An obvious improvement in recognition

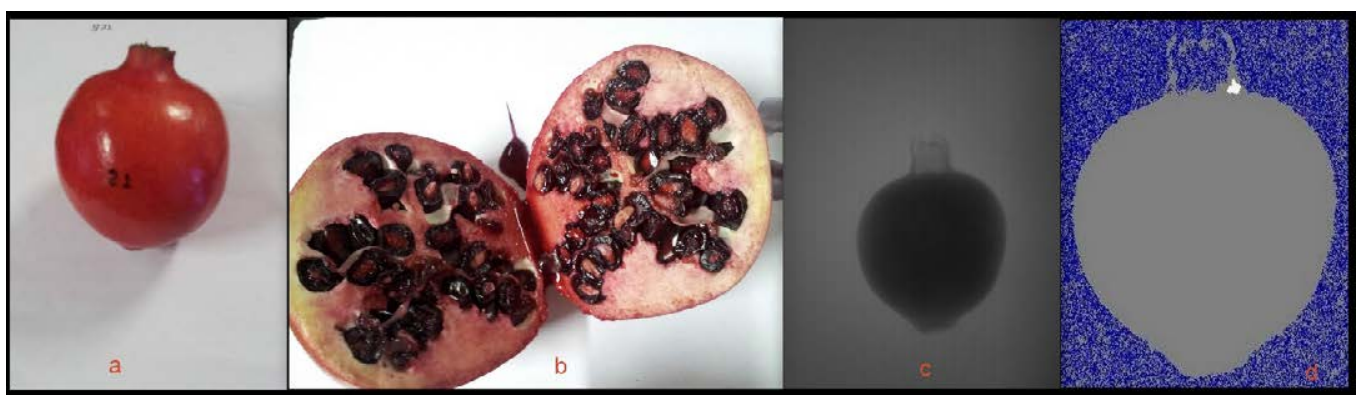

Figure 3: (a) original image; (b) Cut fruit image; (c) X-ray image; (d) Processed RGB image for good fruit.

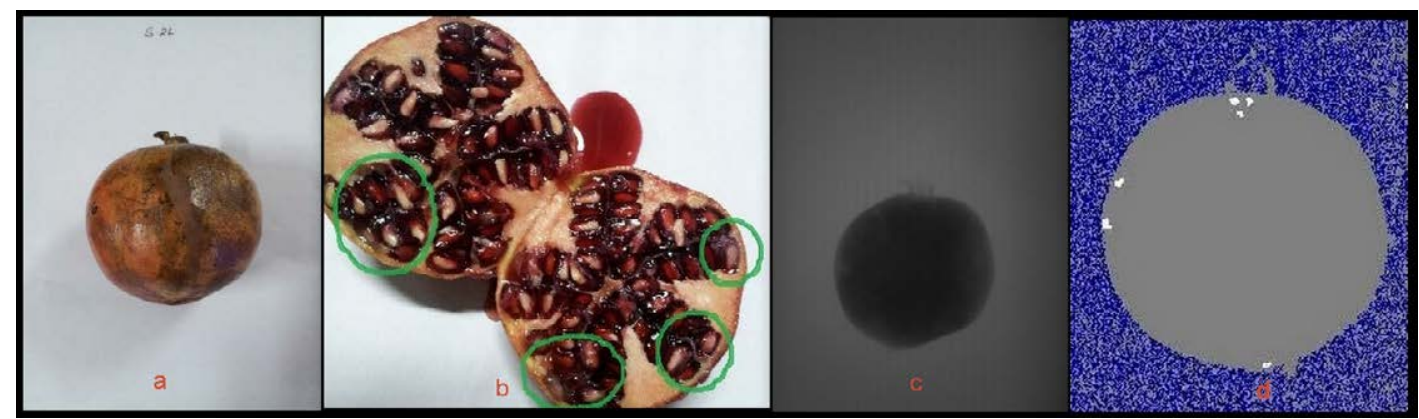

Figure 4: (a) original image; (b) Cut fruit image; (c) X-ray image; (d) Processed RGB image for defective fruit. 
Citation: Payel G, Sunil CK (2014) Quality Analysis of Pomegranate by Non-Destructive Soft X-Ray Method. J Food Process Technol 5: 341. doi:10.4172/2157-7110.1000341

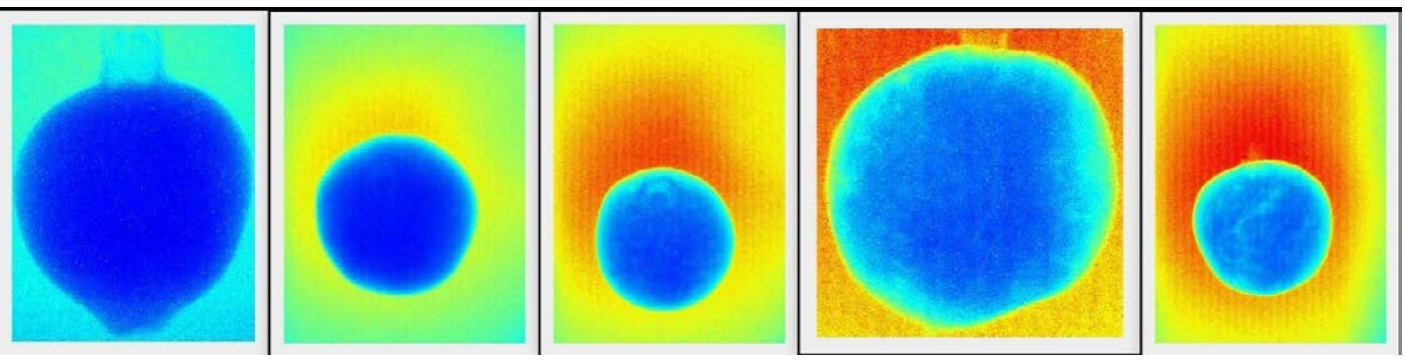

Figure 5: Representation in colour-map; good fruit towards bad fruit (right to left).

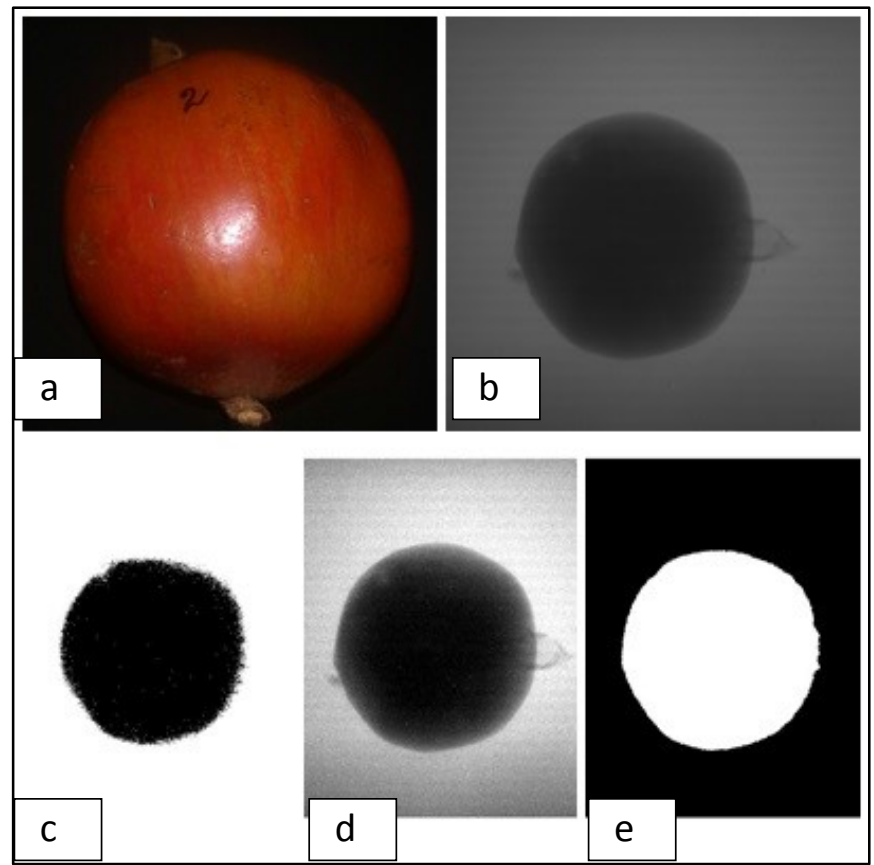

Figure 6: (a) Original image, (b) X-ray image, (c) transformed image, (d) adjusted image and (e) image after filling

capability of the designed system compared to that of the conventional method (visual inspection) was obtained. Thus the propose system and the algorithm is suitable for the improvement of the accuracy and the efficiency of the checking of the internal quality of the fruits. The exact defect is also determined by the area calculation algorithm which shows the value of the defected area in each fruit. In future this developed technology can be a promising computer vision system for detecting the pomegranate with internal and mechanical defects. This will make it easy for maintaining high grade export quality of pomegranate.

\section{Acknowledgement}

The authors are thankful to the Indian Institute of Crop Processing Technology, Ministry of Food processing Industries, Government of India for providing the financial support carrying out the research work.

\section{References}

1. Pekmezci M, Erkan M (2003) Pomegranate. Postharvest quality maintenance guidelines. USDA, Agricultural Research Services. Agriculture Handbook.

2. Pareek OP, Vishal N, Vashishtha BB (2002) Cultivation of arid and desert fruits KrishiMantralaya, Govt of India, New Delhi.

3. Salunkhe DK, Desai BB (1984) Postharvest biotechnology of fruits. CRC Press, Boca Ratonn FL.

4. Butz P, Hofmann C, Tauscher B (2005) Recent developments in non-invasive techniques for fresh fruit and vegetable internal quality analysis. Journal of Food Science70: R131- R141.

5. Kotwaliwale N, Weckler PR, Brusewitz GH, Kranzler GA, Maness NO (2007) Non-destructive quality determination of pecans using soft X-rays. Postharvest biology and technology 45: 372-380.

6. Schatzki TF, Haff RP, Young R, Can I, Le LC, et al. (1997) Defect detection in apples by means of X-ray imaging. Transactions of the ASAE 40: 1407-1415.

7. Shahin MA, Tollner EW, Gitaitis RD, Sumner DR, Maw BW (2002) Classification of sweet onions based on internal defects using image processing and neural network techniques. Transactions of the ASAE 45: 1613-1618.

8. Karunakaran C, Jayas DS, White NDG (2003) Soft X-ray inspection of whea kernels infested by Sitophilusoryzae. Transactions of the ASAE 46: 739-745.

9. Karunakaran C, Jayas DS, White NDG (2004) Detection of infestations by Cryptolestes ferrugineus inside wheat kernels using a soft X-ray method. Canadian Biosystems Engineering 46: 1-7.

10. Jiang JA, Chang HY, Wu KH, Ouyang CS, Yang MM, et al (2008) An adaptive image segmentation algorithm for $X$-ray quarantine inspection of selected fruits. Computers and electronics in agriculture 60: 190-200.

11. Thomas $P$, Kannan A, Degwekar VH, Ramamurthy MS (1995) Non-destructive detection of seed weevil-infested mango fruits by X-ray imaging. Postharvest Biology and Technology 5: 161-165.

12. Reyes MU, Paull RE, Gautz LD, Armstrong JW, Follett PA (1999) Non- 
Citation: Payel G, Sunil CK (2014) Quality Analysis of Pomegranate by Non-Destructive Soft X-Ray Method. J Food Process Technol 5: 341. doi:10.4172/2157-7110.1000341

destructive inspection of mango fruit (Mangifera indica L.) with soft X-ray imaging. In VI International Symposium on Mango 509: 787-792.

13. Haff RP, Slaughter DC, Sarig Y, Kader A (2006) X-ray assessment of translucency in pineapple. Journal of food processing and preservation 30 : 527-533

14. Blasco J, Cubero S, Gómez-Sanchís J, Mira P, Moltó E (2009) Development of a machine for the automatic sorting of pomegranate (Punicagranatum) arils based on computer vision. Journal of Food Engineering 90: 27-34.

15. Morita K, Ogawa Y, Thai CN, Tanaka F (2003) Soft X-Ray Image Analysis to Detect Foreign Materials in Foods. Food Science and Technology Research 9: 137-141.

16. Elizabeth JM, Carlos HC, Adel AK (1996) Pomegranate: Recommendation for maintaining postharvest quality. Department of Plant Sciences, University of California, Perishable handling.
17. Elyatem SM, Kader AA (1984) Post-harvest physiology and storage behaviour of pomegranate fruits. Scientia Horticulturae 24: 287-298.

18. Gonzalez RC, Woods RE (1998) Digital Image Processing. (2 ${ }^{\text {nd }}$ Edition) Addison-Wesley, New York.

19. Jha SN, Matsuoka T (2000) Non-destructive techniques for quality evaluation of intact fruits and vegetables. Food Science and Technology Research 6: 248251.

20. Kiploks EM, O'neil JD (1979) US Patent No 4,156,744. Washington, DC: US Patent and Trademark Office.

21. Noh SH, Choi KH (2006) Nondestructive quality evaluation technology for fruits and vegetables. In International Seminar on Enhancing Export Competitiveness of Asian Fruits, Bangkok, Thailand. 